\section{Interleukin-6 kinetics can be useful for early treatment monitoring of severe bacterial sepsis and septic shock}

\author{
Thomas Klag,' Giulio Cantara, ${ }^{2}$ \\ Udo Sechtem, ${ }^{2}$ Anastasios Athanasiadis ${ }^{2}$ \\ ${ }^{1}$ Division of Gastroenterology and \\ 2Division of Cardiology, Robert-Bosch- \\ Hospital, Stuttgart, Germany
}

\begin{abstract}
Early appropriate anti-microbial therapy is necessary to improve outcomes of septic patients. We describe 20 case histories of patients with severe bacterial sepsis regarding kinetics of several biomarkers. We found that interleukin- 6 is able to predict survival and might be able to evaluate appropriateness of anti-microbial therapy.
\end{abstract}

\section{Introduction}

Appropriate antibiotic therapy for bacterial sepsis is one of the most important therapeutic challenges, as mortality clearly depends on this issue. ${ }^{1}$ Therefore, most therapeutic strategies rely on an initial appropriate and broad spectrum antibiotic use. Resistance of numerous bacterial species evolved as a major clinical problem, especially in intensive care units (ICUs). ${ }^{2}$ Additionally, from an economic point of view, unnecessary antibiotic use is highly expensive overall. ${ }^{3}$ Hence, unnecessary or inappropriate anti-microbial therapy should be avoided for medical and economic reasons.

On the other hand, at the beginning of bacterial sepsis, clinicians are often forced to make decisions regarding the change of antimicrobial therapy, especially within the first hours. ${ }^{4}$ Unfortunately, until today no concluding and approved clinical parameters are available to support those decisions. ${ }^{5}$ Because of their dynamics $\mathrm{C}$ reactive protein (CRP) and procalcitonin (PCT) alone are not good enough to support treatment monitoring in these very early stages of sepsis. ${ }^{6}$ Studies regarding PCT guided anti-microbial therapy decisions for example, did not show improvement of patient outcomes. Thus PCT is regarded as investigational, concerning appropriateness or change of anti-microbial therapy in sepsis. ${ }^{7,8}$ Therefore, even if the chosen anti-microbial strategy is appropriate, early therapy of bacterial sepsis is often guided by personal experi- ences and expert opinions rather than laboratory markers and evidence based approaches.

In 2013 Jekarl et al. were able to show that in serial measurements (follow-up in the first 96 hours of sepsis) interleukin-6 (IL-6) is a more reliable parameter than CRP and PCT to distinguish between survivors and non-survivors in bacterial sepsis. ${ }^{9}$ In their cohort, $86 \%$ of the survivors showed a decline in IL- 6 levels after 48 hours, in contrast to non-survivors. Therefore the authors proposed that IL-6 exhibits better dynamics for monitoring antimicrobial sepsis therapy. However, in their cohort they observed only 16 patients with severe sepsis or septic shock and serial PCT, IL-6 and CRP measurements were available for only nine patients (6 non-survivors; 3 survivors). Therefore, they stated that additional data are needed to underline their observations and we intend to do so with the data we present in this brief report.

\section{Materials and Methods}

We analyzed charts of patients who were admitted to our ICU between 07/2012 to $08 / 2013$ with the diagnosis of severe sepsis or septic shock according to the criteria of Angus and van der Poll, ${ }^{1}$ and for whom serial IL-6, CRP, PCT and white blood cell count (WBC) measurements were available. 20 patients met these criteria. For patient characteristics, detected microbes, anti-microbial therapy and baseline values of IL-6, CRP, PCT and WBC see Table 1. The summarized kinetics of IL-6, CRP, PCT and WBC are shown in Figure 1. To illustrate the biomarker kinetics data are depicted as relative fold change between mean baseline values and the mean values after 24,48 and 72 hours.

\section{Results}

In our study IL-6 showed a rapid decrease in survivors whereas in the non-survivor-group there was a delayed decrease or even an increase in the first 24-48 hours. Interestingly, CRP and PCT showed an initial decrease only after 48 hours in the survivor group, at a time when the relative IL- 6 decrease had already become significant. In contrast, WBC was still rising at 72 hours in our survivor cohort (Figure 1). Additionally, in the survivor group we were able to observe a significant increase of CRP after 24 hours. Therefore, in this setting IL-6 seems to be the only predictor of appropriate (anti-microbial) therapy in the first 24-48 hours of severe bacterial sepsis and septic shock. In the non-survivor group none of the studied biomarkers declined during the
Correspondence: Thomas Klag, Division of Gastroenterology, Robert-Bosch-Hospital, Auerbachstrasse 110, 70376 Stuttgart, Germany. Tel.: +49.711.8101.5598 - Fax: +49.711 .8101 .3791 . E-mail: thomas.klag@gmx.de

Key words: Interleukin-6; C reactive protein; procalcitonin; bacterial sepsis; monitoring.

Contributions: TK, GC, US, AA, study concept and design, drafting of the manuscript, critical revision of the manuscript for important intellectual content; TK, GC, acquisition of data, analysis and interpretation of data, statistical analysis.

Conflict of interest: the authors declare no potential conflict of interest.

Received for publication: 27 September 2015.

Revision received: 8 January 2016.

Accepted for publication: 25 January 2016.

This work is licensed under a Creative Commons Attribution-NonCommercial 4.0 International License (CC BY-NC 4.0).

CC Copyright T. Klag et al., 2016

Licensee PAGEPress, Italy

Infectious Disease Reports 2016; 8:6213

doi:10.4081/idr.2016.6213

observed time period (Figure 1). Regarding the absolute baseline values, only WBC was significantly higher in the non-survivor group compared to survivors (Table 1). The other biomarkers showed no significant baseline value differences between the two groups (Table 1).

Jekarl et al. made similar observations in their cohort and hypothesized that the observed IL- 6 decline might be related to the appropriateness of the chosen antibiotic therapy regimen, although they did not have data supporting their hypothesis. ${ }^{9}$

In our cohort we observed that the initially chosen antibiotic therapy was appropriate in $10 / 14$ survivors (71\%) in whom etiological organisms could be detected e.g. by blood, urine and/or bronchial lavage cultures. For 4/14 survivors no microbes could be detected, but an infectious focus was confirmed e.g. by radiological imaging.

In the non-survivor group 4/6 patients (67\%) were treated with appropriate therapy according to the detected microbes, but in most of these patients at least two different microbes were detected. Therefore, these patients were challenged with a broader bacterial spectrum. For one patient of the non-survivor group the initial antibiotic therapy was not appropriate (necrotizing pancreatitis) and for another patient no etiological organism could be detected. 

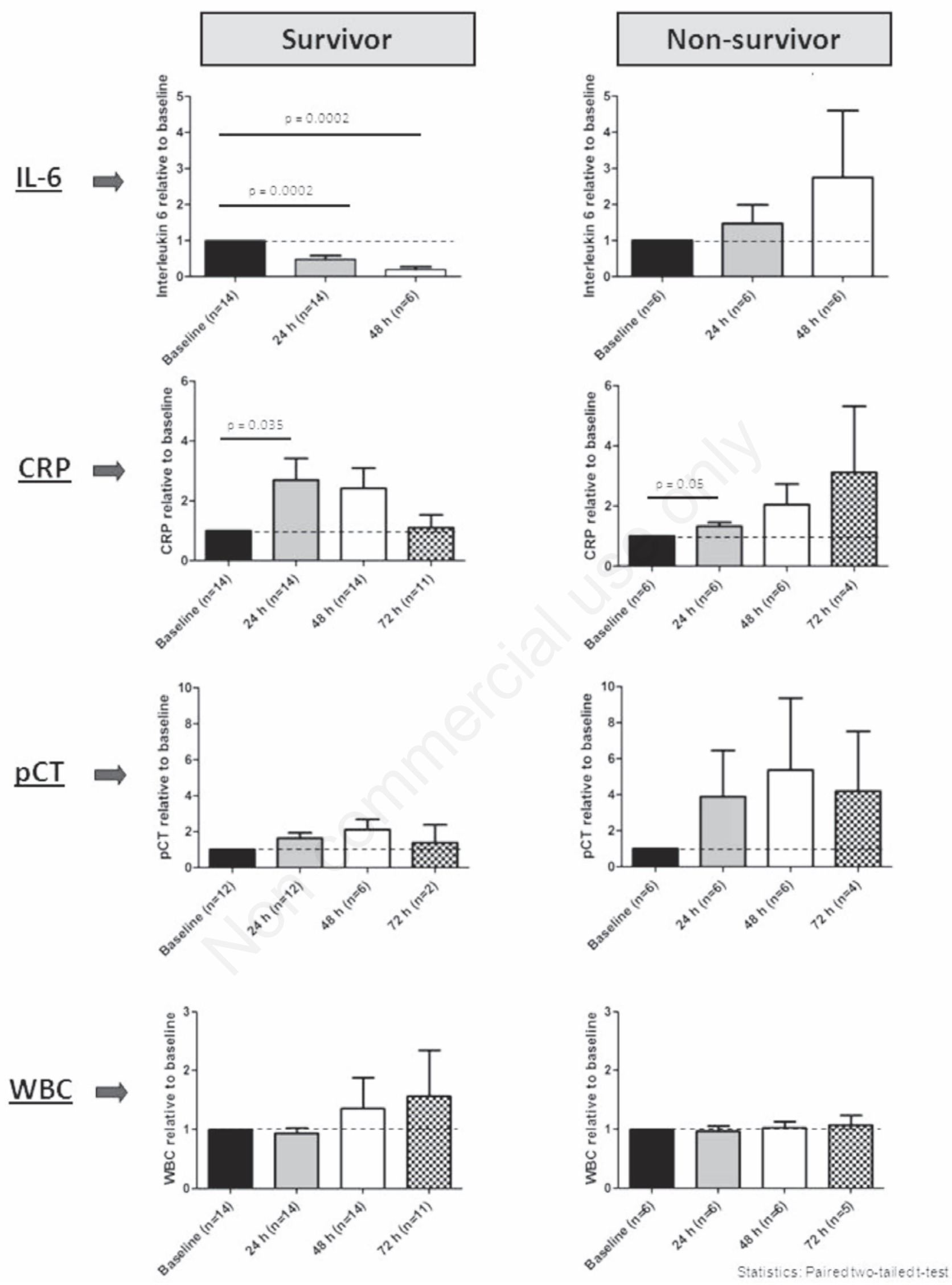

Figure 1. Relative biomarker kinetics of IL-6, CRP, PCT and WBC for survivors and non-survivors in the first 72 hours after start of sepsis therapy. Values are plotted relatively, as fold change of baseline values (all mean values). For statistical testing the paired twotailed t-test was used. A $\mathbf{P}<0.05$ is considered as statistically significant. 
Table 1. Characteristics of patients and etiological organisms. All patients were diagnosed with severe bacterial sepsis or septic shock according to the criteria of Angus and van der Poll 2013. Mean baseline values for IL-6, CRP, PCT and WBC are summarized. A P<0.05 is considered as statistically significant (t-test).

\begin{tabular}{|c|c|c|c|c|}
\hline & $\begin{array}{c}\text { Total } \\
(n=20)\end{array}$ & Survivor $(\mathrm{n}=14)$ & Non-survivor $(\mathrm{n}=6)$ & P-value \\
\hline \multicolumn{5}{|l|}{ Sex } \\
\hline Female & $5(25 \%)$ & $4(28.6 \%)$ & $1(16.7 \%)$ & - \\
\hline Male & $15(75 \%)$ & $10(71.4 \%)$ & $5(83.3 \%)$ & - \\
\hline Age, year & $72 \pm 11.2$ & $71.07 \pm 12.2$ & $77.3 \pm 7.3$ & 0.26 \\
\hline \multicolumn{5}{|l|}{ Microbes } \\
\hline Gram + cocci & 1 & 1 & - & - \\
\hline E. coli & 2 & 1 & 1 & - \\
\hline Pneumococci & 1 & 1 & - & - \\
\hline Morganella morganii & 1 & 1 & - & - \\
\hline Staph. aureus & 3 & 2 & 1 & - \\
\hline Staph. epidermidis & 1 & 1 & - & - \\
\hline Klebsiella pneumoniae & 1 & 1 & - & - \\
\hline Hafnia alvei & 1 & 1 & - & - \\
\hline Candida albicans & 3 & 1 & 2 & - \\
\hline Proteus mirabilis & 1 & 1 & - & - \\
\hline Clostridium difficile & 1 & 1 & - & - \\
\hline Pseudomonas aeruginosa & 1 & 1 & - & - \\
\hline Enterobacter cloacae & 1 & 1 & - & - \\
\hline Enterococcus faecium & 3 & - & 3 & - \\
\hline Aspergillus fumigatus & 1 & - & 1 & - \\
\hline$M R S E$ & 1 & - & 1 & - \\
\hline$>1$ microbe per patient & $5(25 \%)$ & $1(7 \%)$ & $4(67 \%)$ & - \\
\hline$<1$ microbe per patient & $15(75 \%)$ & $13(93 \%)$ & $2(33 \%)$ & - \\
\hline Antibiotics used in the first $72 \mathrm{hrs}$ & - & $\begin{array}{c}\text { Ceftriaxone/Clarithomyc } \\
\text { in } 3 \text { (21\%); Ceftriaxone } 5 \text { (36\%); } \\
\text { Ciprofloxacin } 2 \text { (14\%); } \\
\text { Meropenem } 2 \text { (14\%); } \\
\text { Piperacillin + } \\
\text { Tazobactam } 2 \text { (14\%) }\end{array}$ & $\begin{array}{c}\text { Ceftriaxone/Clarithomycin } 1 \text { (17\%); } \\
\text { Ceftriaxone } 2 \text { (34\%); } \\
\text { Ciprofloxacin } 1 \text { (17\%); } \\
\text { Levofloxacin } 1 \text { (17\%); } \\
\text { Piperacillin + Tazobactam } 1 \text { (17\%) }\end{array}$ & - \\
\hline \multicolumn{5}{|l|}{ Tested markers (baseline values) } \\
\hline IL-6, ng/mL & $2.42 \pm 6.12$ & $2.61 \pm 7.1$ & $1.97 \pm 3.87$ & 0.42 \\
\hline pCT, ng/mL & $23.37 \pm 46.92$ & $19.15 \pm 34.5$ & $31.81 \pm 68.87$ & 0.3 \\
\hline $\mathrm{CRP}, \mathrm{mg} / \mathrm{dL}$ & $14.93 \pm 11.75$ & $13.37 \pm 9.72$ & $18.57 \pm 16.01$ & 0.19 \\
\hline WBC, GIGA/L & $13.84 \pm 6.11$ & $12.35 \pm 5.84$ & $17.32 \pm 5.53$ & 0.047 \\
\hline
\end{tabular}

\section{Conclusions}

Our data confirm that a rapid decline of IL-6 in the first 24-48 hours (before microbial cultures are available) could be a useful tool to identify patients in whom anti-microbial therapy will be successful. The small size of our patient sample is of course a limitation. However, our data are in agreement with those of Jekarl et al. ${ }^{9}$ A prospective analysis of the outcome of an IL-6-guided anti-microbial sepsis-therapy is necessary before this approach can be recommended for general use.

\section{References}

1. Angus DC, van der Poll T. Severe sepsis and septic shock. N Engl J Med 2013;369:840-51.

2. De Santis V, Gresoiu M, Corona A, et al. Bacteraemia incidence, causative organisms and resistance patterns, antibiotic strategies and outcomes in a single university hospital ICU: continuing improvement between 2000 and 2013. J Antimicrob Chemother 2015;70:273-8.

3. Burns J. Do health plans have a role in limiting antibiotic resistance? Manag Care 2014;23:26-33.

4. Davies SW, Efird JT, Guidry CA, et al. Characteristics of surgical patients receiving inappropriate empiric antimicrobial therapy. J Trauma Acute Care Surg 2014;77:546-54.

5. Rodriguez-Maresca M, Sorlozano A, Grau $\mathrm{M}$, et al. Implementation of a computerized decision support system to improve the appropriateness of antibiotic therapy using local microbiologic data. Biomed Res Int 2014;2014:395434.

6. Faix JD. Biomarkers of sepsis. Crit Rev Clin Lab Sci 2013;50:23-36.

7. Sridharan P, Chamberlain RS. The efficacy of procalcitonin as a biomarker in the management of sepsis: slaying dragons or tilting at windmills? Surg Infect (Larchmt) 2013;14:489-511.

8. Jensen JU, Hein L, Lundgren B, et al. Procalcitonin-guided interventions against infections to increase early appropriate antibiotics and improve survival in the intensive care unit: a randomized trial. Crit Care Med 2011;39:2048-58.

9. Jekarl DW, Lee SJ, Lee J, et al. Procalcitonin as a diagnostic marker and IL-6 as a prognostic marker for sepsis. Diagn Microbiol Infect Dis 2013;75:342-7. 